\title{
Modelling of Batch Lactic Acid Fermentation in the Presence of Anionic Clay
}

\author{
Cosmin Jinescu' ${ }^{1}$, Vasilica Alisa Aruş², Oana Cristina Pârvulescu ${ }^{3 *}$ and \\ Ileana Denisa Nistor ${ }^{2}$
}

${ }^{1}$ Politehnica University of Bucharest, Mechanical Engineering Department, 313 Splaiul Independenței, RO-060042 Bucharest, Romania

${ }^{2}$ Vasile Alecsandri University of Bacău, Chemical and Food Engineering Department, 157 Mărășești, RO-600115 Bacău, Romania

${ }^{3}$ Politehnica University of Bucharest, Chemical and Biochemical Engineering Department, 1-3 Gheorghe Polizu, RO-011061 Bucharest, Romania

Received: October 30, 2013

Accepted: October 1, 2014

\begin{abstract}
Summary
Batch fermentation of milk inoculated with lactic acid bacteria was conducted in the presence of hydrotalcite-type anionic clay under static and ultrasonic conditions. An experimental study of the effect of fermentation temperature $\left(t=38-43{ }^{\circ} \mathrm{C}\right)$, clay/milk ratio $(R=1-7.5 \mathrm{~g} / \mathrm{L})$ and ultrasonic field $(v=0$ and $35 \mathrm{kHz})$ on process dynamics was performed. A mathematical model was selected to describe the fermentation process kinetics and its parameters were estimated based on experimental data. A good agreement between the experimental and simulated results was achieved. Consequently, the model can be employed to predict the dynamics of batch lactic acid fermentation with values of process variables in the studied ranges. A statistical analysis of the data based on a $2^{3}$ factorial experiment was performed in order to express experimental and model-regressed process responses depending on $t, R$ and $v$ factors.
\end{abstract}

Key words: anionic clay, fermentation, lactic acid, mass transfer, modelling, ultrasound, yoghurt

\section{Introduction}

The key process in biotechnology used to obtain fermented (cultured) dairy products is lactic acid fermentation, a microaerophilic process consisting mainly in converting lactose to lactic acid (LA) in the presence of lactic acid bacteria (LAB), e.g. from genera Lactobacillus, Streptococcus, Lactococcus or Leuconostoc. Based on their optimal growth temperature, these LAB can be either thermophilic (Lactobacillus and Streptococcus), characterized by an optimum temperature of around $42{ }^{\circ} \mathrm{C}$, or mesophilic (Lactococcus and Leuconostoc), having an optimum temperature of around $26^{\circ} \mathrm{C}(1,2)$.

Many studies confirm that the cell growth is inhibited by the accumulation of LA in the fermentation broth (3-7).
In order to avoid this inhibitory effect of the produced LA, various methods of LA removal from the broth during fermentation have been investigated, e.g. solvent extraction (8-10), electrodialysis (11-13), adsorption onto activated carbon (14) or molecular sieves (3), and retention onto anion exchange resins $(4,6,7,15-18)$, each with its own limitations. The toxicity of organic solvents for the cells is an important disadvantage of solvent extraction. Electrodialysis implies high capital costs for large scale operation and it is not economically feasible. Generally, adsorption and ion exchange processes require a subsequent removal of the adsorbent or ion exchange particles from the system. Additional chemicals (salt solutions) are necessary to recover the LA from ion exchangers (3). 
In situ LA removal from a characteristic fermentation medium (yoghurt) preparation by its retention onto hydrotalcite-type anionic clay has been studied in this paper. Yoghurt is commonly produced by the fermentation of full or skimmed milk in the presence of specific LAB in the following stages: (i) milk standardization, (ii) milk homogenization, (iii) heat treatment of standardized and homogenized milk, (iv) cooling to fermentation (incubation) temperature, $(v)$ inoculation with starter culture, (vi) fermentation (incubation) and (vii) cooling $(1,2,19)$.

Standardization stage involves an adjustment of milk total solid (fat, proteins, lactose and mineral matter) content, whereas milk homogenization consists of fat globule disruption into smaller ones (1,19-21). Conventional heat treatment of standardized and homogenized milk can be conducted at $80-85^{\circ} \mathrm{C}$ for $30 \mathrm{~min}$ or at $90-95^{\circ} \mathrm{C}$ for $5-10$ $\min (1,2,19)$. The heat treatment mainly aims at destroying the unwanted microorganisms as well as at reducing the concentration of dissolved oxygen in order to assist the starter culture growth $(2,19)$. After its thermal processing, the milk is cooled to fermentation (incubation) temperature and is further inoculated with an individual or a mixed LAB starter culture. In the fermentation stage, the milk lactose is partially converted to LA (by means of $\mathrm{LAB}$ ), resulting in a decrease in the $\mathrm{pH}$ and an aggregation of milk proteins forming a cross-linked gel network which has pores containing aqueous phase (whey) (19). When the yoghurt attains the desired $\mathrm{pH}$ level, i.e. 4.1-4.7, it is quickly cooled, usually to $5-10^{\circ} \mathrm{C}$, and further stored at $2-5{ }^{\circ} \mathrm{C}$ in order to diminish the culture metabolic activity, otherwise some defects may occur, e.g. high acidity or distinct acetaldehyde flavour $(1,2,19)$.

A good quality yoghurt should have high viscosity and strength (firmness), characteristic flavour, creamy texture, low whey separation (syneresis), and recommended values of $\mathrm{pH}$ and viable LAB. Rheological (viscosity and gel strength), sensory (flavour, creaminess and whey separation) and microbial (viable LAB content) properties of yoghurt are influenced by the characteristics of starter culture (type and inoculation rate) and milk (composition, homogenization and heat treatment conditions) as well as by fermentation conditions (temperature and final $\mathrm{pH}$ value).

Typically, a mixed starter culture of Streptococcus thermophilus (S. thermophilus) and Lactobacillus delbruekii ssp. bulgaricus (L. bulgaricus) is used in yoghurt production $(1,2,19-24)$. A ratio of bacterial species of $1: 1$ and inoculation rates of $0.5-4 \%$ (by mass) are recommended in order to obtain an optimal cell growth and good yoghurt properties $(1,22,24)$. Due to a symbiotic relationship between bacterial species in the mixed culture, a higher growth rate and faster LA production in comparison with those of the individual cultures have been reported $(1,2)$. Both species are thermophilic (S. thermophilus bacterium exhibits an optimal growth at $39{ }^{\circ} \mathrm{C}$, L. bulgaricus at $45^{\circ} \mathrm{C}$, and mixed culture at $42-43^{\circ} \mathrm{C}$ ) and can convert homofermentatively the lactose into LA as a main product (1). Besides LA, the LAB yield low amounts of acetaldehyde, diacetyl, acetone, acetic acid, formic acid and other compounds contributing to characteristic yoghurt flavour (1,20-23). From a physiological point of view, the fermentation process consists of two stages. In the first stage, L. bulgaricus stimu- lates the growth of $S$. thermophilus, releasing short peptides and essential amino acids from casein, whereas in the second stage, $S$. thermophilus produces formic acid and carbon dioxide, which enhance the growth of L. bulgaricus $(1,2,24)$. These LAB should be viable and abundant (the International Dairy Federation recommends a concentration of at least $10^{7}$ colony-forming units (CFU) per $g$ ) in the fermented product in order to have beneficial effects on digestive and immune system of consumers $(2,21,23)$.

Milk processing has important effects on the yoghurt properties. Accordingly, an increase in gel viscosity and strength was observed at larger values of milk total solid content as well as a grainy texture and significant syneresis at a high milk mineral matter content $(1,20)$. During conventional heat treatment of milk, an increase in gel viscosity and strength, a decrease in whey separation and faster gelation were reported at higher temperatures, i.e. 90-95 ${ }^{\circ} \mathrm{C}(1,2,19)$.

The incubation temperature, usually ranging from 38 to $48^{\circ} \mathrm{C}$, influences the cell growth, fermentation time and gel microstructure. Lower incubation temperatures (38-40 $\left.{ }^{\circ} \mathrm{C}\right)$ lead to a lower cell growth rate, longer fermentation time and highly cross-linked protein network with small pores, yielding an increase in gel viscosity, strength and creaminess (smoothness) along with a decrease in whey separation $(1,19)$. Final $\mathrm{pH}$ values between 4.1 and 4.7 are recommended in order to achieve appropriate cell growth and a good gel quality $(1,2,19-22)$. A higher value of the final $\mathrm{pH}$ (4.6-4.7), implying a shorter fermentation time, conduces to a less firm and viscous gel having a higher concentration of viable $\mathrm{LAB}$ and a more pronounced whey separation in comparison with a lower $\mathrm{pH}$ value (4.1-4.2) (1). A maximum number of viable cells at $\mathrm{pH}$ values ranging between 5.0 and 5.5 as well as a significant decrease in their number at $\mathrm{pH}$ from 5.0-5.5 to 4.1-4.7 were reported $(1,14)$. An addition of hydrotalcite-type anionic clay to the fermentation broth at $\mathrm{pH}=5.0-5.5$, in order to retain some LA produced by lactose conversion, followed by a lactic acid fermentation stopping at $\mathrm{pH}=4.6$ 4.7 could promote the bacterial growth by reducing the LA concentration. This could result in an increase in gel strength, viscosity, creaminess and viable LAB number as well as in a decrease in whey separation. It was reported that a direct contact of an anion exchange resin with characteristic LAB of yoghurt preparation did not affect the cell activity (17).

The anionic clays consist of positively charged sheets of mixed metal hydroxides between which exchangeable anions and water molecules are located. Having diffraction patterns very similar or identical to that of hydrotalcite, i.e. $\mathrm{Mg}_{6} \mathrm{Al}_{2}\left(\mathrm{CO}_{3}\right)(\mathrm{OH})_{16} \cdot 4 \mathrm{H}_{2} \mathrm{O}$, they have also been referred to as hydrotalcites, hydrotalcite-like compounds or hydrotalcite-type anionic clays (25-27). Unlike the anion exchange resins, the anionic clays are less expensive and can be easily prepared in laboratory. Moreover, hydrotalcites are ingestible and widely used as antacid, antipepsin and gastric mucosa protection agents in the pharmaceutical industry $(26,28-32)$. Accordingly, due to their beneficial health effects, they can be added to the fermented dairy product.

The retention of LA on porous anionic clay is strongly influenced by the contact conditions between the fermen- 
tation medium and clay particles. Ultrasonication is commonly applied as an efficient technique to intensify the mass transfer in solid-liquid adsorption processes. Ultrasound cavitation can produce a turbulence in the liquid phase, leading to a decrease in the boundary layer (static liquid film surrounding the adsorbent particle) thickness and an increase in the mass transfer rate $(33,34)$.

This paper focuses on modelling of batch fermentation of skimmed milk inoculated with LAB as well as on selection of favourable operation parameters to obtain a high yoghurt quality along with low energy and material expenses. Lactic acid fermentation was conducted in the presence of hydrotalcite-type anionic clay, with and without ultrasound field, at different operation temperatures and clay/milk ratios.

\section{Materials and Methods}

\section{Preparation and characterization of hydrotalcite-type anionic clay}

For the synthesis of hydrotalcite-type anionic clay, coprecipitation method at low supersaturation and constant $\mathrm{pH}$ was selected, being the most frequently used method to prepare the anionic clays (25-27,35-39). Solution A, consisting of $1 \mathrm{~mol}$ of $\mathrm{Mg}\left(\mathrm{NO}_{3}\right)_{2} \cdot 6 \mathrm{H}_{2} \mathrm{O}$ and $0.2 \mathrm{~mol}$ of $\mathrm{Al}\left(\mathrm{NO}_{3}\right)_{3} \cdot 9 \mathrm{H}_{2} \mathrm{O}$ dissolved in $700 \mathrm{~mL}$ of distilled water, and solution $\mathrm{B}$, containing $3.5 \mathrm{~mol}$ of $\mathrm{NaOH}$ and $0.943 \mathrm{~mol}$ of $\mathrm{Na}_{2} \mathrm{CO}_{3}$ in $1 \mathrm{~L}$ of distilled water, were prepared at $35^{\circ} \mathrm{C}$. All reagents were purchased from Sigma-Aldrich $(\mathrm{Mu}-$ nich, Germany) and were used without further purification. The solutions were mixed by dropwise addition of solution A to solution B under vigorous stirring, with the $\mathrm{pH}$ kept at about 10. After precipitation completion, the slurry was aged at $65{ }^{\circ} \mathrm{C}$ for $18 \mathrm{~h}$ under continuous stirring. The precipitate was filtered, washed with distilled water to remove $\mathrm{NaNO}_{3}$ and further dried at $100{ }^{\circ} \mathrm{C}$ for $18 \mathrm{~h}$.

Hydrotalcite-like compound synthesis was confirmed by X-ray diffraction (XRD) analysis conducted on a Siemens D5000 X-ray Diffractometer (Siemens, Munich, Germany) using $\mathrm{Cu} \mathrm{K} \alpha$ radiation $(\lambda=1.5406 \AA$ ). Specific surface area, pore size distribution and mean pore diameter of hydrotalcite-type anionic clay were evaluated based on nitrogen adsorption/desorption isotherms at $77 \mathrm{~K}$ obtained by means of a Coulter SA 3100 surface area and pore size analyzer (Beckman Coulter, Krefeld, Germany) (36).

\section{Yoghurt starter culture preparation}

In order to prepare a yoghurt starter culture, low-fat $(1.5 \%)$ homogenized and high-temperature $\left(85^{\circ} \mathrm{C}\right)$ pasteurized milk was heated at $42{ }^{\circ} \mathrm{C}$ and inoculated with a lyophilized mixed starter culture (Chr. Hansen FD-DVS YC-X11 Yo-Flex, Chr. Hansen, Hørsholm, Denmark), containing the species $S$. thermophilus and L. bulgaricus. Inoculation was carried out according to the producer's recommendations. Lactic acid fermentation was performed at 42 ${ }^{\circ} \mathrm{C}$ until the $\mathrm{pH}$ value dropped to $4.6-4.7$, the yoghurt was further cooled to $10^{\circ} \mathrm{C}$, and then stored at $(4 \pm 1)^{\circ} \mathrm{C}$.

\section{Fermentation medium preparation}

Low-fat (1.5\%) homogenized and high-temperature $\left(85^{\circ} \mathrm{C}\right)$ pasteurized milk, which was heated to the operation temperature and further inoculated with the yoghurt starter culture, was used as a fermentation medium. A milk volume of $0.40 \mathrm{~L}$ was vigorously mixed with $0.06 \mathrm{~L}$ of yoghurt and the mixture was poured into four heat-resistant glass beakers, each containing $0.1 \mathrm{~L}$ of milk and 0.015 $\mathrm{L}$ of yoghurt. The beakers were covered and then put into the experimental fermentation set-up.

\section{Experimental set-up}

The experimental set-up used to study the batch lactic acid fermentation consisted of a stainless steel ultrasonic bath (Retsch UR1, Haan, Germany), operated at an ultrasound frequency of $35 \mathrm{kHz}$, and a Thermo Haake B12 temperature-controlled circulating water bath (Thermo Electron, Karlsruhe, Germany), as shown in Fig. 1. The baths were coupled, ball valve was opened, circulating water bath was filled with water to a standard level, operational parameters (temperature and circulating pump flow rate) were set, circulating pump and heating were started. When the operation temperature value was obtained, four covered beakers containing the fermentation medium were put in a stainless steel basket and placed

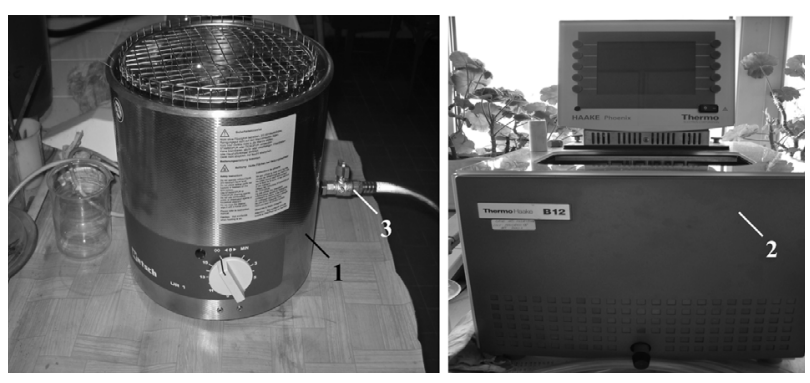

Fig. 1. Experimental set-up $(1=$ ultrasonic bath, $2=$ temperature-controlled circulating water bath, $3=$ ball valve)

into the ultrasonic bath (1). Water continually circulated through the baths in order to maintain a constant temperature $\left( \pm 0.1^{\circ} \mathrm{C}\right)$ during fermentation and water level in the ultrasonic bath was controlled by the ball valve. The $\mathrm{pH}$ values of the fermentation medium were measured by an InoLab pH Level 2 digital pH-meter (WTW, Weilheim in Oberbayern, Germany) with an accuracy of $\pm 0.005 \mathrm{pH}$ units. At a pH value of 5.0-5.1, when the LAB growth was considered optimal, various masses of anionic clay, namely $0.1,0.5$ and $0.75 \mathrm{~g}$, were added to the fermentation medium in three beakers, under vigorous stirring conditions, i.e. $100 \mathrm{rpm}$ for about 3 min using a Heidolph RZR 1 mechanical stirrer (Heidolph Instruments, Schwabach, Germany), obtaining a homogeneous and stable suspension. LA retention onto anionic clay was obtained with or without ultrasound field (ultrasonic or static runs, respectively). Lactic acid fermentation was stopped at $\mathrm{pH}=4.6-4.7$, the yoghurt was cooled to $10{ }^{\circ} \mathrm{C}$, stored at $(4 \pm 1){ }^{\circ} \mathrm{C}$ for 3 days and further analyzed.

\section{Experimental variables}

Batch lactic acid fermentation was conducted under static $\left(v_{1}=0 \mathrm{kHz}\right)$ and ultrasonic $\left(v_{2}=35 \mathrm{kHz}\right)$ conditions, at 
three operation temperatures $\left(t_{1}=38^{\circ} \mathrm{C}, t_{2}=43^{\circ} \mathrm{C}\right.$ and $t_{3}=48$ $\left.{ }^{\circ} \mathrm{C}\right)$ and four anionic clay/milk ratios $\left(R_{0}=0 \mathrm{~g} / \mathrm{L}, R_{1}=1 \mathrm{~g} / \mathrm{L}\right.$, $R_{2}=5 \mathrm{~g} / \mathrm{L}$ and $\left.R_{3}=7.5 \mathrm{~g} / \mathrm{L}\right)$. Each experiment was replicated three times in order to determine its reproducibility.

The $\mathrm{pH}$ value of the fermentation medium was continuously recorded as a function of fermentation time, $\tau$. Because the ratio between the concentration of LA and the total concentration of the other acids in the characteristic fermentation broth of yoghurt preparation is usually more than 9 (1), it was assumed that the contribution of the other acids to the titratable acidity as well as their retention onto the clay particles were negligible. The values of LA concentration in the liquid phase, $\gamma_{\mathrm{LA}}$, were estimated by a linear interpolation of $\gamma_{\mathrm{LA}, \exp }=\mathrm{f}(\mathrm{pH})$ experimental data, where the values of $\gamma_{\mathrm{LA}, \exp }$ were determined by titration with $0.1 \mathrm{M} \mathrm{NaOH}$ in the presence of phenolphthalein indicator (36).

\section{Physical and microbiological analyses of yoghurt}

Yoghurt mass, viscosity, syneresis and viable LAB concentration were measured after 3 days of storage at $(4 \pm 1){ }^{\circ} \mathrm{C}$. Rheological tests were conducted using a Rheotest 2 rotary viscosimeter (MLW, Munich, Germany) equipped with coaxial cylinders. Yoghurt viscosity was determined at $(4 \pm 0.1){ }^{\circ} \mathrm{C}$ for a shear rate ranging from 0.5 to $437 \mathrm{~s}^{-1}$. Syneresis was estimated by transferring a yoghurt sample to a funnel covered with Whatman filter paper (Sigma-Aldrich). The funnel was placed on a conical flask and stored at $(4 \pm 1)^{\circ} \mathrm{C}$ for $3 \mathrm{~h}$. Afterwards the mass of the separated whey was weighed and syneresis index, $S$ (\%), was calculated as whey mass (g) per $100 \mathrm{~g}$ of sample.
Viable LAB concentration was evaluated by enumeration on appropriate agar media in Petri dishes using standard procedures (1,40-42). Accordingly, S. thermophilus was enumerated on M17 agar (Difco Laboratories, Detroit, MI, USA) after aerobic incubation at $37^{\circ} \mathrm{C}$ for $24 \mathrm{~h}$ and L. bulgaricus on MRS (De Man-Rogosa-Sharpe) agar with $\mathrm{pH}$ value adjusted to 5.2 (Difco Laboratories) after anaerobic incubation at $45^{\circ} \mathrm{C}$ for $72 \mathrm{~h}$.

\section{Results and Discussion}

\section{Characterization of hydrotalcite-type anionic clay}

Anionic clay particles with a mean diameter of 0.006 $\mathrm{cm}$ and a density of $0.97 \mathrm{~g} / \mathrm{cm}^{3}$ were obtained by coprecipitation. A particle specific surface area of $3.6 \cdot 10^{5} \mathrm{~cm}^{2} / \mathrm{g}$, a predominantly mesoporous structure of clay particle and a mean pore diameter of $12.5 \mathrm{~nm}$ were estimated based on nitrogen adsorption/desorption isotherms at $77 \mathrm{~K}$.

\section{Lactic acid fermentation}

Characteristic experimental data of LA concentration in the liquid phase obtained under static and ultrasonic conditions, at various process temperatures and clay/milk ratios are depicted in Figs. 2 and 3. All experiments were triplicated and values of relative standard dispersions less than $5 \%$ were obtained, indicating a good reproducibility. Final values of fermentation time, which are listed in Table 1 and shown in Fig. 4, decreased with the increase of operation temperature and the decrease of clay/milk ratio, and were higher in the presence of ultrasound field.
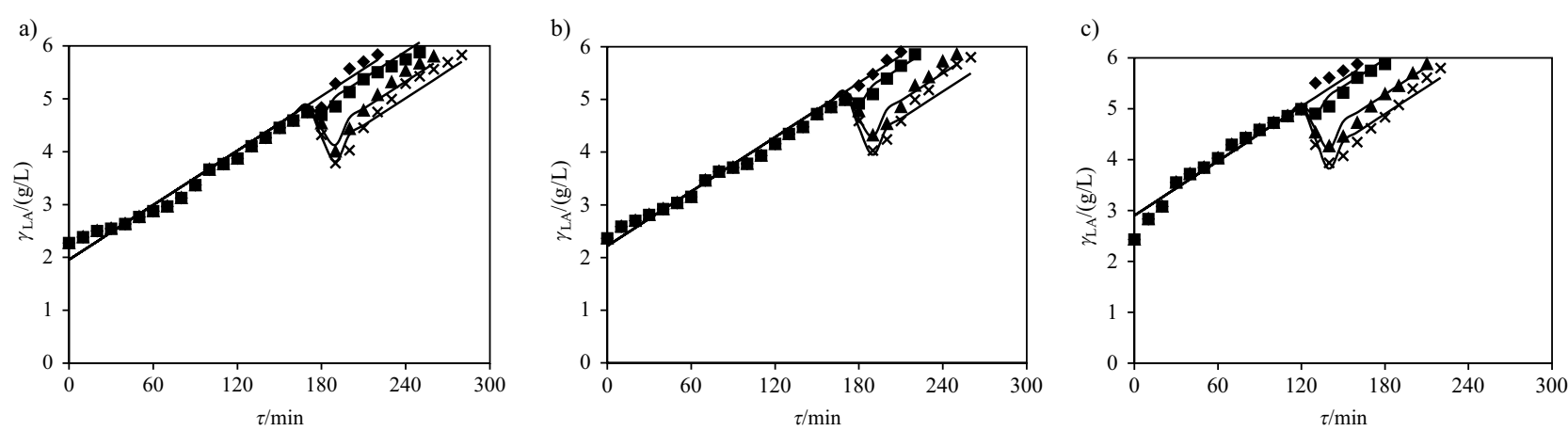

Fig. 2. Lactic acid (LA) concentration in the liquid phase vs. fermentation time in static runs at various values of clay/milk ratio $((m / V) /(\mathrm{g} / \mathrm{L})): \bullet R_{0}=0, \boldsymbol{\square} R_{1}=1, \Delta R_{2}=5, \times R_{3}=7.5$ and temperature $\left.\left.\left({ }^{\circ} \mathrm{C}\right): \mathrm{a}\right) t_{1}=38, \mathrm{~b}\right) t_{2}=43$, and c) $t_{3}=48$; symbol=experimental, line $=$ calculated

a)

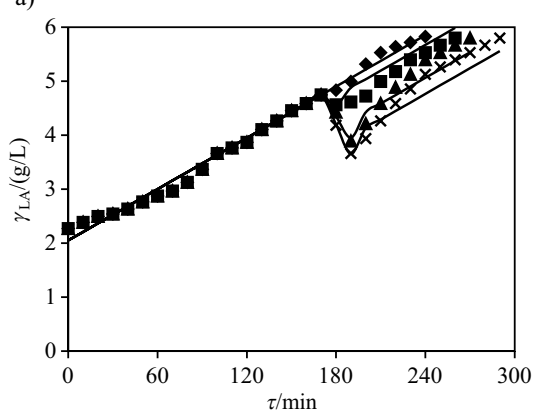

b)

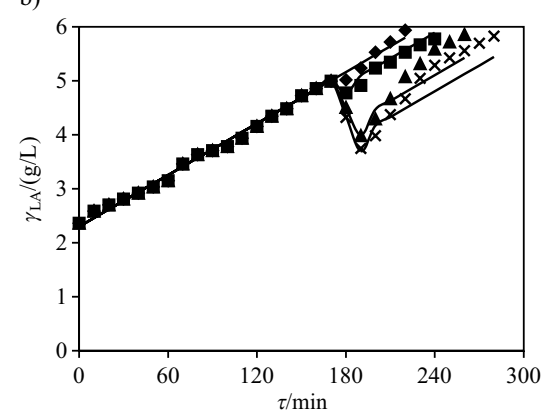

c)

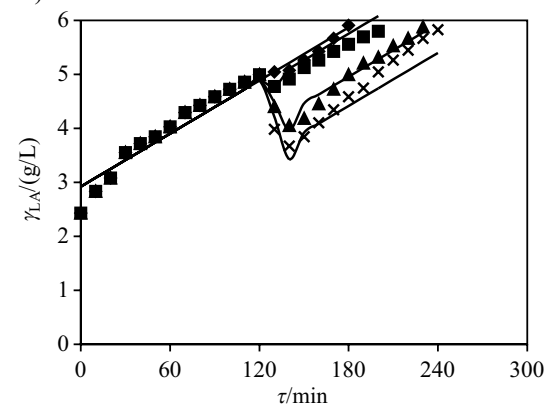

Fig. 3. Lactic acid (LA) concentration in the liquid phase $v s$. fermentation time in ultrasonic runs at various values of clay/milk ratio $((\mathrm{m} / \mathrm{V}) /(\mathrm{g} / \mathrm{L})): \bullet R_{0}=0, \boldsymbol{\bullet} R_{1}=1, \Delta R_{2}=5, \times R_{3}=7.5$ and temperature $\left.\left.\left({ }^{\circ} \mathrm{C}\right): \mathrm{a}\right) t_{1}=38, \mathrm{~b}\right) t_{2}=43$, and c) $t_{3}=48$; symbol=experimental, line $=$ calculated 
Table 1. Influence of experimental variables on fermentation process kinetics

\begin{tabular}{|c|c|c|c|c|c|c|c|c|c|}
\hline Run & $\frac{v}{\mathrm{kHz}}$ & $\frac{t}{{ }^{\circ} \mathrm{C}}$ & $\frac{R}{\mathrm{~g} / \mathrm{L}}$ & $\frac{\tau_{\mathrm{f}}}{\min }$ & $\frac{\Delta \tau_{\max }}{\min }$ & $\frac{v_{\mathrm{g}} \cdot 10^{2}}{\mathrm{~g} /(\mathrm{L} \cdot \min )}$ & $\frac{\gamma_{\mathrm{LA}, \text { min }}}{\mathrm{g} / \mathrm{L}}$ & $\frac{s_{\mathrm{LA}, \mathrm{eq}}}{\mathrm{g} / \mathrm{g}}$ & $\frac{k_{\mathrm{LA}}}{\mathrm{cm} / \mathrm{min}}$ \\
\hline 1 & 0 & 38 & 0 & 220 & 70 & 1.716 & - & - & 0.0000 \\
\hline 2 & 0 & 38 & 1 & 250 & 90 & 1.716 & 4.696 & 0.225 & 0.0047 \\
\hline 3 & 0 & 38 & 5 & 260 & 110 & 1.716 & 4.005 & 0.194 & 0.0020 \\
\hline 4 & 0 & 38 & 7.5 & 280 & 120 & 1.716 & 3.811 & 0.171 & 0.0018 \\
\hline 5 & 0 & 43 & 0 & 210 & 70 & 1.722 & - & - & 0.0000 \\
\hline 6 & 0 & 43 & 1 & 220 & 80 & 1.722 & 4.923 & 0.243 & 0.0049 \\
\hline 7 & 0 & 43 & 5 & 250 & 110 & 1.722 & 4.319 & 0.210 & 0.0021 \\
\hline 8 & 0 & 43 & 7.5 & 260 & 120 & 1.722 & 4.027 & 0.310 & 0.0019 \\
\hline 9 & 0 & 48 & 0 & 160 & 70 & 1.788 & - & - & 0.0000 \\
\hline 10 & 0 & 48 & 1 & 180 & 90 & 1.788 & 4.902 & 0.270 & 0.0054 \\
\hline 11 & 0 & 48 & 5 & 210 & 120 & 1.788 & 4.265 & 0.228 & 0.0023 \\
\hline 12 & 0 & 48 & 7.5 & 220 & 140 & 1.788 & 3.937 & 0.204 & 0.0020 \\
\hline 13 & 35 & 38 & 0 & 240 & 80 & 1.584 & - & - & 0.0000 \\
\hline 14 & 35 & 38 & 1 & 260 & 100 & 1.584 & 4.562 & 0.350 & 0.0073 \\
\hline 15 & 35 & 38 & 5 & 270 & 120 & 1.584 & 3.893 & 0.220 & 0.0023 \\
\hline 16 & 35 & 38 & 7.5 & 290 & 130 & 1.584 & 3.660 & 0.190 & 0.0020 \\
\hline 17 & 35 & 43 & 0 & 220 & 70 & 1.590 & - & - & 0.0000 \\
\hline 18 & 35 & 43 & 1 & 240 & 90 & 1.590 & 4.777 & 0.374 & 0.0075 \\
\hline 19 & 35 & 43 & 5 & 260 & 120 & 1.590 & 3.982 & 0.264 & 0.0026 \\
\hline 20 & 35 & 43 & 7.5 & 280 & 130 & 1.590 & 3.750 & 0.216 & 0.0022 \\
\hline 21 & 35 & 48 & 0 & 180 & 80 & 1.638 & - & - & 0.0000 \\
\hline 22 & 35 & 48 & 1 & 200 & 100 & 1.638 & 4.773 & 0.383 & 0.0077 \\
\hline 23 & 35 & 48 & 5 & 230 & 130 & 1.638 & 4.050 & 0.270 & 0.0027 \\
\hline 24 & 35 & 48 & 7.5 & 240 & 150 & 1.638 & 3.675 & 0.252 & 0.0025 \\
\hline
\end{tabular}

$R=m$ (clay) $/ V$ (milk); $\tau_{\mathrm{f}}=$ final fermentation time; $\Delta \tau_{\max }=$ period of maximum cell growth; $v_{\mathrm{g}}=$ lactic acid (LA) generation rate; $\gamma_{\mathrm{LA}, \min }=$ minimum LA concentration in the liquid phase in the presence of anionic clay; $s_{\mathrm{LA}, \mathrm{eq}}=$ equilibrium LA concentration in the solid phase; $k_{\mathrm{LA}}=$ mass transfer coefficient in the liquid film
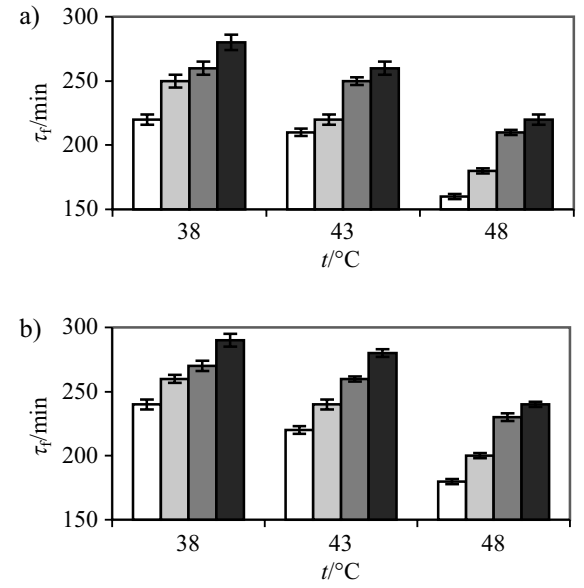

Fig. 4. Final fermentation time (mean values \pm standard deviation) $v s$. operation temperature under: a) static and b) ultrasonic conditions at various values of clay/milk ratio $((\mathrm{m} / \mathrm{V}) /$ $(\mathrm{g} / \mathrm{L})): \square R_{0}=0, \quad R_{1}=1, \quad R_{2}=5, \square R_{3}=7.5$

\section{Lactic acid fermentation in the absence of anionic clay}

A linear variation of LA concentration in the liquid phase, $\gamma_{\mathrm{LA}}$, with fermentation time, $\tau$, can be observed in the blank runs $\left(R_{0}=0 \mathrm{~g} / \mathrm{L}\right)$; consequently the LA generation rate, $v_{\mathrm{g}}$ can be considered constant in time. Data present- ed in Fig. 5 show this linear dependency as well as the values of $v_{g^{\prime}}$ estimated as line slope, for static and ultrasonic blank runs conducted at $t_{2}=43{ }^{\circ} \mathrm{C}$, i.e. 0.0172 and
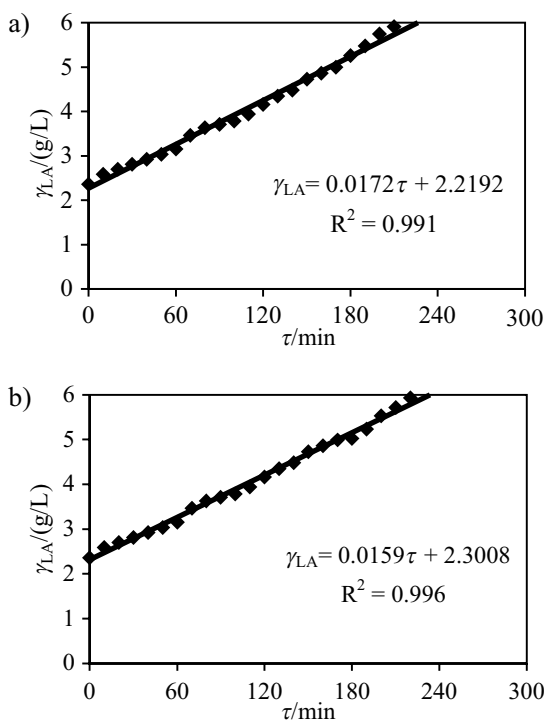

Fig. 5. Lactic acid (LA) concentration in the liquid phase vs. fermentation time in: a) static and b) ultrasonic blank runs $\left(R_{0}=0\right.$ $\mathrm{g} / \mathrm{L})$ at $t_{2}=43^{\circ} \mathrm{C}$ 
$0.0159 \mathrm{~g} /(\mathrm{L} \cdot \mathrm{min})$. Values of $v_{\mathrm{g}}$, which are listed in Table 1 and shown in Fig. 6, slightly increased with the increase of operation temperature and were lower in the presence of ultrasound field. A decrease in LA generation rate in ultrasonic runs can be a consequence of cell disruption caused by cavitation (33).

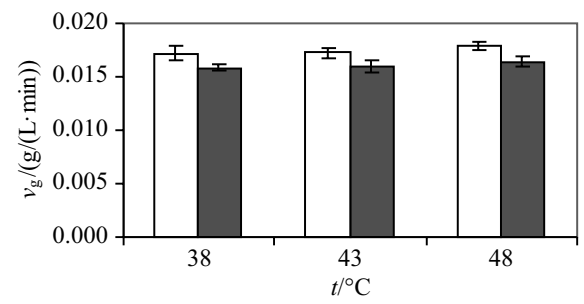

Fig. 6. Lactic acid generation rate (mean values \pm standard deviation) vs. operation temperature in static $(\square)$ and ultrasonic ( blank runs $\left(R_{0}=0 \mathrm{~g} / \mathrm{L}\right)$

\section{Lactic acid fermentation in the presence of anionic clay}

Experimental results of batch lactic acid fermentation dynamics obtained under various operation conditions in the presence of anionic clay (Figs. 2 and 3) highlight that the LA concentration in the liquid phase, $\gamma_{\mathrm{LA}}$, has a linear variation in time from initial $\mathrm{pH}=6.0-6.1\left(\gamma_{\mathrm{LA}, 0}=2.272-2.430\right.$ $\mathrm{g} / \mathrm{L})$ to $\mathrm{pH}=5.0-5.1\left(\gamma_{\mathrm{LA}}=4.745-4.993 \mathrm{~g} / \mathrm{L}\right)$, when the anionic clay is added and, in ultrasonic runs, when the ultrasonic bath is started. After the clay addition, $\gamma_{\mathrm{LA}}$ decreases with fermentation time until the clay reaches the saturation state, when LA concentration in the liquid phase obtains a minimum value, $\gamma_{\mathrm{LA}, \mathrm{min}}$. The $\gamma_{\mathrm{LA}}$ decreases more sharply and $\gamma_{\mathrm{LA} \text {,min }}$ values are lower at higher values of clay/milk ratio. Moreover, $\gamma_{\mathrm{LA}, \min }$ values, which are listed in Table 1 and shown in Fig. 7, are lower in ultrasonic runs. After the clay saturation, $\gamma_{\mathrm{LA}}$ increases with fermentation time until $\mathrm{pH}=4.6-4.7\left(\gamma_{\mathrm{LA}}=5.801-5.935 \mathrm{~g} / \mathrm{L}\right)$, when the fermentation process is stopped.
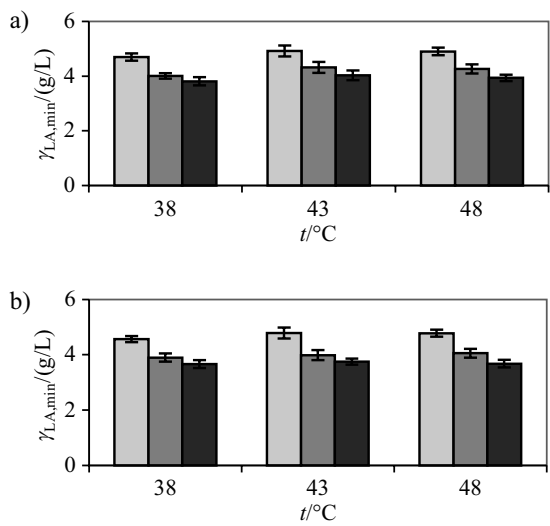

Fig. 7. Minimum lactic acid (LA) concentration in the liquid phase in the presence of anionic clay (mean values \pm standard deviation) vs. operation temperature under: a) static and b) ultrasonic conditions at various values of clay/milk ratio $((\mathrm{m} / \mathrm{V}) /$ $(\mathrm{g} / \mathrm{L})): \quad R_{1}=1, \square R_{2}=5, \square R_{3}=7.5$

Considering that a maximum cell number was obtained at $\mathrm{pH}=5.0-5.5\left(\gamma_{\mathrm{LA}}=3.753-4.993 \mathrm{~g} / \mathrm{L}\right)$, this period of maximum cell growth, estimated using Eq. 1, lasted about
$70-80 \mathrm{~min}$ at $R_{0}=0 \mathrm{~g} / \mathrm{L}, 80-100 \mathrm{~min}$ at $R_{1}=1 \mathrm{~g} / \mathrm{L}, 110-130$ min at $R_{2}=5 \mathrm{~g} / \mathrm{L}$ and $120-150 \mathrm{~min}$ at $R_{3}=7.5 \mathrm{~g} / \mathrm{L}$, as shown in Table 1. Moreover, tabulated data emphasize that $\Delta \tau_{\max }$ values are slightly higher in ultrasonic runs performed in the presence of anionic clay than in static runs. Accordingly, the viable LAB number could be larger in the yoghurt containing anionic clay which was prepared under ultrasonic operation conditions.

$$
\Delta \tau_{\max }=\left.\tau\right|_{\gamma_{\mathrm{LA} \cong 5}}-\left.\tau\right|_{\gamma_{\mathrm{LA} 33.8}}
$$

\section{Modelling of lactic acid fermentation accompanied by $L A$ retention onto anionic clay}

To describe the retention process of species from the liquid phase onto the adsorbent or ion exchange particles, simple or complex models can be selected, depending on the simplifying assumptions, equations and restrictions considered $(3,4,6,7,18)$.

The model adopted to predict the species (LA) retention onto hydrotalcite-type anionic clay particles in batch operation is based on the following simplifying assumptions: (i) anionic clay particles have a predominately mesoporous structure, spherical shape, same size $\left(r_{\mathrm{P}}=0.003\right.$ $\mathrm{cm}$ ) and are surrounded by a static liquid film (boundary layer), (ii) mesopore mean diameter $(12.5 \mathrm{~nm})$ is much larger than LA molecule size $(0.62 \mathrm{~nm})$, (iii) pore diffusion resistance is negligible (fine adsorbent particles with large pores), (iv) species mass transfer in the film occurs by ordinary molecular diffusion in a planar medium $\left(\delta » r_{\mathrm{P}}\right)$ and a quasi-stationary state, $(v)$ the species concentrations at the particle-liquid film interface are estimated by an interphase equilibrium relationship, (vi) the external solution is perfectly mixed, and (vii) the system operates under isothermal conditions.

The mean diameter of LA molecule, $d_{\mathrm{LA}}$, was estimated applying Eq. 2, where $M_{\mathrm{LA}}$ is LA molecular mass $\left(M_{\mathrm{LA}}=90 \mathrm{~g} / \mathrm{mol}\right), \rho_{\mathrm{LA}}$ is LA density $\left(\rho_{\mathrm{LA}}=1209 \mathrm{~g} / \mathrm{L}\right)$ and $N_{\mathrm{A}}$ is Avogadro's number $\left(N_{\mathrm{A}}=6.023 \cdot 10^{23} \mathrm{~mol}^{-1}\right)$.

$$
d_{\mathrm{LA}}=\sqrt[3]{\frac{6 M_{\mathrm{LA}}}{1000 \pi \rho_{\mathrm{LA}} N_{\mathrm{A}}}}=0.62 \cdot 10^{-9} \mathrm{~m}
$$

Characteristic equations and restrictions of the retention process of molecular species (LA) from the liquid phase onto anionic clay particles consist of conservation equation in the liquid phase (Eq. 3), conservation in the solid phase (Eq. 4), diffusion in the liquid film (Eq. 5), equilibrium relationship at the particle-liquid film interface (Eq. 6), initial conditions (Eq. 7) and boundary conditions (Eq. 8).

$$
\begin{gathered}
V \frac{\mathrm{d} \gamma_{\mathrm{LA}}}{\mathrm{d} \tau}=V v_{\mathrm{g}}-4 \pi r_{\mathrm{P}}^{2} n_{\mathrm{P}} J_{\mathrm{LA}}= \\
=V v_{\mathrm{g}}-\frac{3}{r_{\mathrm{P}}} V_{\mathrm{S}} J_{\mathrm{LA}} \\
\rho_{\mathrm{P}} \frac{\mathrm{d} s_{\mathrm{LA}}}{\mathrm{d} \tau}=\frac{3}{r_{\mathrm{P}}} J_{\mathrm{LA}} \\
J_{\mathrm{LA}}=D_{\mathrm{LA}} \frac{\gamma_{\mathrm{LA}}-\gamma_{\mathrm{LA}}^{\mathrm{i}}}{\delta}=k_{\mathrm{LA}}\left(\gamma_{\mathrm{LA}}-\gamma_{\mathrm{LA}}^{\mathrm{i}}\right)
\end{gathered}
$$




$$
\begin{gathered}
\frac{\gamma_{\mathrm{LA}}^{\mathrm{i}}}{s_{\mathrm{LA}}}=K_{\mathrm{d}, \mathrm{LA}} \\
\tau=0 ; 0 \leq r_{\mathrm{d}}<r_{\mathrm{P}} ; s_{\mathrm{LA}}\left(r_{\mathrm{d}}, 0\right)=0 \\
\tau=0 ; r_{\mathrm{d}}=r_{\mathrm{P}} ; s_{\mathrm{LA}}\left(r_{\mathrm{P}}, 0\right)=s_{\mathrm{LA}}^{\mathrm{i}}(0)=0 ; \\
\gamma_{\mathrm{LA}}\left(r_{\mathrm{P}}, 0\right)=\gamma_{\mathrm{LA}}^{\mathrm{i}}(0)=0 \\
\tau=0 ; r_{\mathrm{d}} \geq r_{\mathrm{P}}+\delta ; \gamma_{\mathrm{LA}}\left(r_{\mathrm{d}}, 0\right)=\gamma_{\mathrm{LA}}(0)=\gamma_{\mathrm{LA}, 0} \\
\tau>0 ; 0 \leq r_{\mathrm{d}}<r_{\mathrm{P}} ; s_{\mathrm{LA}}\left(r_{\mathrm{d}}, \tau\right)=s_{\mathrm{LA}}(\tau)=s_{\mathrm{LA}} \\
\tau>0 ; r_{\mathrm{d}}=r_{\mathrm{P}} ; s_{\mathrm{LA}}\left(r_{\mathrm{P}}, \tau\right)=s_{\mathrm{LA}}^{\mathrm{i}}(\tau)=s_{\mathrm{LA}}^{\mathrm{i}} ; \\
\gamma_{\mathrm{LA}}\left(r_{\mathrm{P}}, \tau\right)=\gamma_{\mathrm{LA}}^{\mathrm{i}}(\tau)=\gamma_{\mathrm{LA}}^{\mathrm{i}} \\
\tau>0 ; r_{\mathrm{d}} \geq r_{\mathrm{P}}+\delta ; \gamma_{\mathrm{LA}}\left(r_{d}, \tau\right)=\gamma_{\mathrm{LA}}(\tau)=\gamma_{\mathrm{LA}}
\end{gathered}
$$

Combining Eqs. 3-6, respectively, the following independent equation system was obtained:

$$
\begin{array}{r}
\frac{\mathrm{d} \gamma_{\mathrm{LA}}}{\mathrm{d} \tau}=v_{\mathrm{g}}-\frac{3}{r_{\mathrm{P}}} \frac{V_{\mathrm{S}}}{V} k_{\mathrm{LA}}\left(\gamma_{\mathrm{LA}}-K_{\mathrm{d}, \mathrm{LA}} S_{\mathrm{LA}}\right)= \\
=v_{\mathrm{g}}-\frac{3}{r_{\mathrm{P}}} \frac{m_{\mathrm{S}}}{\rho_{\mathrm{P}} V} k_{\mathrm{LA}}\left(\gamma_{\mathrm{LA}}-K_{\mathrm{d}, \mathrm{LA}} s_{\mathrm{LA}}\right) \\
\frac{\mathrm{d} s_{\mathrm{LA}}}{\mathrm{d} \tau}=\frac{3}{r_{\mathrm{P}}} \frac{1}{\rho_{\mathrm{P}}} k_{\mathrm{LA}}\left(\gamma_{\mathrm{LA}}-K_{\mathrm{d}, \mathrm{LA}} s_{\mathrm{LA}}\right)
\end{array}
$$

Characteristic parameters of model equations and restrictions are as follows: species concentration in the liquid phase, $\gamma_{\mathrm{LA}}\left(\mathrm{g} / \mathrm{cm}^{3}\right)$; species concentration at the particle-liquid film interface $\gamma_{\mathrm{LA}}^{\mathrm{i}}\left(\mathrm{g} / \mathrm{cm}^{3}\right)$; minimum species concentration in the liquid phase in the presence of anionic clay, $\gamma_{\mathrm{LA}, \min }\left(\mathrm{g} / \mathrm{cm}^{3}\right)$; species diffusion coefficient in the liquid film, $D_{\text {LA }}\left(\mathrm{cm}^{2} / \mathrm{s}\right)$; species mass flux, $J_{\text {LA }}(\mathrm{g} /$ $\left.\left(\mathrm{cm}^{2} \cdot \mathrm{s}\right)\right)$; species mass transfer coefficient in the liquid film, $k_{\mathrm{LA}}(\mathrm{cm} / \mathrm{s})$; species distribution coefficient, $K_{\mathrm{d}, \mathrm{LA}}\left(\mathrm{g} / \mathrm{cm}^{3}\right)$; solid mass, $m_{\mathrm{S}}(\mathrm{g})$; particle number, $n_{\mathrm{p}}$; radial distance, $r_{\mathrm{d}}$ (cm); clay particle radius, $r_{\mathrm{P}}=0.003 \mathrm{~cm}$; species concentration in the solid phase, $s_{\mathrm{LA}}(\mathrm{g} / \mathrm{g})$; equilibrium (saturation) species concentration in the solid phase, $s_{\mathrm{LA}, \text { eq }}(\mathrm{g} / \mathrm{g})$; species generation rate, $v_{\mathrm{g}}\left(\mathrm{g} /\left(\mathrm{cm}^{3} \cdot \mathrm{s}\right)\right)$; solution volume, $V\left(\mathrm{~cm}^{3}\right)$; solid volume, $V_{\mathrm{S}}\left(\mathrm{cm}^{3}\right)$; liquid film thickness, $\delta(\mathrm{cm}) ;$ particle density, $\rho_{\mathrm{P}}=0.97 \mathrm{~g} / \mathrm{cm}^{3}$; fermentation time, $\tau$ (s).

The equation and restriction system in Eqs. 7-10 was solved by the fourth order Runge-Kutta method. The species generation rate, $v_{\mathrm{g}}$, was estimated based on the experimental data obtained in the blank runs and the distribution coefficient was determined in a previous work, i.e. $K_{\mathrm{d}, \mathrm{LA}}=0.06 \mathrm{~g} / \mathrm{cm}^{3}$ (38). The species mass transfer coefficient in the liquid film, $k_{\mathrm{LA}}$, was calculated from the experimental data by the least squares method, by minimizing the objective function:

$$
f\left(k_{\mathrm{LA}}\right)=\sum_{\tau}\left[\gamma_{\mathrm{LA}}(\tau)-\gamma_{\mathrm{LA}, \exp }(\tau)\right]^{2}
$$

Based on Eqs. 9 and 10 and considering that the anionic clay is added to the fermentation medium at $\mathrm{pH}=5.0$ $5.1\left(\gamma_{\mathrm{LA}, \text { add }}=4.745-4.993 \mathrm{~g} / \mathrm{L}\right)$, as well as that the fermentation process is stopped at $\mathrm{pH}=4.6-4.7\left(\gamma_{\mathrm{LA}, \text { stop }}=5.801-5.935\right.$ $\mathrm{g} / \mathrm{L})$, the equation system describing the batch fermentation kinetics in the presence of anionic clay can be written as:

$$
\begin{aligned}
& \frac{\mathrm{d} \gamma_{\mathrm{LA}}}{\mathrm{d} \tau}=\left\{\begin{array}{l}
v_{\mathrm{g}} \gamma_{\mathrm{LA}, 0} \leq \gamma_{\mathrm{LA}} \leq \gamma_{\mathrm{LA}, \text { add }} \\
v_{\mathrm{g}}-\frac{3}{r_{\mathrm{P}}} \frac{m_{\mathrm{S}}}{\rho_{\mathrm{P}} V} k_{\mathrm{LA}}\left(\gamma_{\mathrm{LA}}-K_{\mathrm{d}, \mathrm{LA}} s_{\mathrm{LA}}\right) \\
v_{\mathrm{g}} \gamma_{\mathrm{LA}, \min }<\gamma_{\mathrm{LA}} \leq \gamma_{\mathrm{LA}, \text { stop }} s_{\mathrm{LA}}>s_{\mathrm{LA}, \mathrm{eq}}
\end{array}\right. \\
& \gamma_{\mathrm{LA}, \text { add }}<\gamma_{\mathrm{LA}} \leq \gamma_{\mathrm{LA}, \min } 0 \leq s_{\mathrm{LA}} \leq s_{\mathrm{LA}, \text { eq }}
\end{aligned}
$$

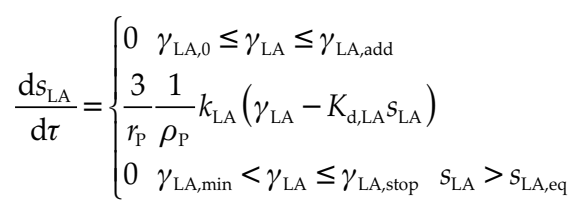

$$
\begin{aligned}
& \gamma_{\mathrm{LA}, \text { add }}<\gamma_{\mathrm{LA}} \leq \gamma_{\mathrm{LA}, \min } \quad 0 \leq s_{\mathrm{LA}} \leq s_{\mathrm{LA}, \mathrm{eq}}
\end{aligned}
$$

Characteristic curves of batch lactic fermentation dynamics, $\gamma_{\text {LA }}(\tau)$, predicted by the equation system in Eq. 12 are shown in Figs. 2 and 3. A good agreement between experimental and simulated data was observed (root mean squared errors were less than 0.07).

The influence of experimental variables on the equilibrium (saturation) species concentration in the solid phase, $s_{\text {LA,eq, }}$ and the species mass transfer coefficient in the liquid film, $k_{\mathrm{LA}}$ is summarized in Table 1. Bars in Figs. 8 and 9 highlight that the values of $s_{\mathrm{LA}, \text { eq }}$ and $k_{\mathrm{LA}}$ are larger in
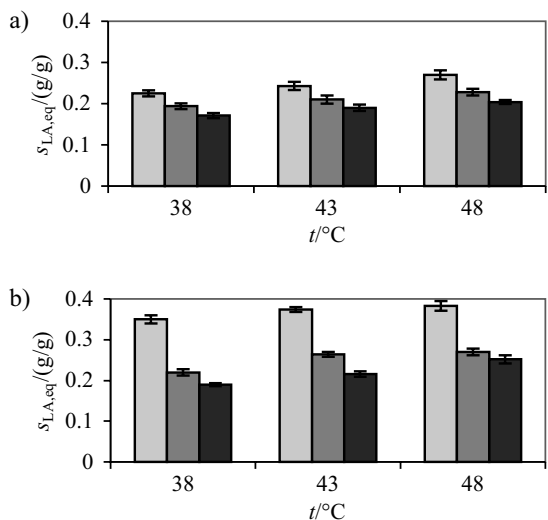

Fig. 8. Equilibrium (saturation) species concentration in the solid phase (mean values \pm standard deviation) vs. operation temperature under: a) static and b) ultrasonic conditions at various values of clay/milk ratio $((m / V) /(\mathrm{g} / \mathrm{L}))$ : $\quad R_{1}=1, \quad R_{2}=5, \square R_{3}=7.5$
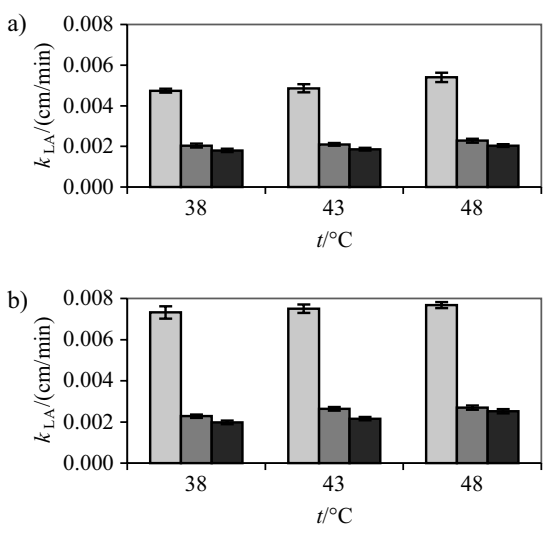

Fig. 9. Species mass transfer coefficient in the liquid film (mean values \pm standard deviation) vs. operation temperature under: a) static and b) ultrasonic conditions at various values of clay/milk ratio $((m / V) /(\mathrm{g} / \mathrm{L}))$ : $\quad R_{1}=1, \quad R_{2}=5, \quad R_{3}=7.5$ 
ultrasonic runs, they increase with the increase of operation temperature and decrease with the increase of clay/ milk ratio. Moreover, values obtained for $s_{\text {LA,eq }}(0.171-0.383$ $\mathrm{g} / \mathrm{g}$ ) and for $k_{\mathrm{LA}}(0.0018$ to $0.0077 \mathrm{~cm} / \mathrm{min}$ ) are in agreement with data reported in the literature referring to batch lactic acid fermentation in the presence of anion exchangers, e.g. $0.342-0.417 \mathrm{~g} / \mathrm{g}$ and $0.0073 \mathrm{~cm} / \mathrm{min}$, respectively $(6,7,18)$.

\section{Yoghurt characterization}

Hourly production, $P(\mathrm{~g} / \mathrm{h})$, expressed as a ratio between the yoghurt mass and final fermentation time; dynamic viscosity, $\eta$ (Pa.s); syneresis index, $S(\%)$; and viable LAB number, $N(\mathrm{CFU} / \mathrm{g})$ of the yoghurt produced by lactic acid fermentation are shown in Figs. 10-13. Depicted data, which are consistent with values reported in other studies $(1,40-43)$, reveal a low viscosity and a significant syneresis of the product yielded at the highest temperature $\left(t_{3}=48\right.$ $\left.{ }^{\circ} \mathrm{C}\right)$, as well as a low production and a pronounced syneresis of the yoghurt obtained at the highest clay/milk ratio $\left(R_{3}=7.5 \mathrm{~g} / \mathrm{L}\right)$. Moreover, a grainy structure of the yoghurt
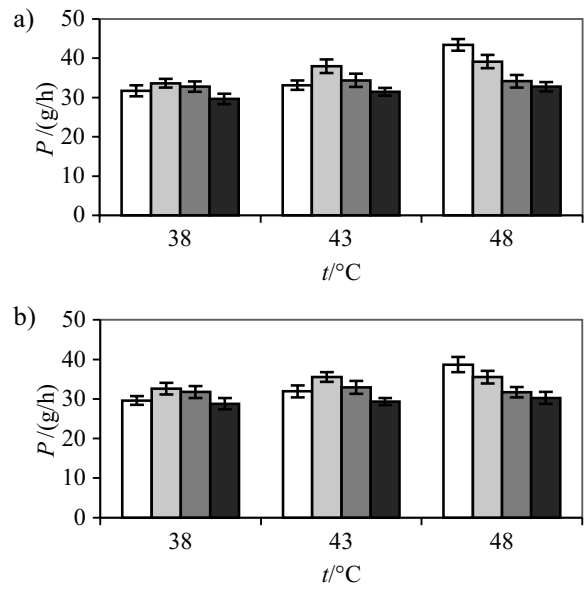

Fig. 10. Yoghurt production (mean values \pm standard deviation) $v s$. operation temperature under: a) static and b) ultrasonic conditions at various values of clay/milk ratio $((m / V) /(\mathrm{g} / \mathrm{L})): \square R_{0}=0$, $R_{1}=1, \quad R_{2}=5, \square R_{3}=7.5$
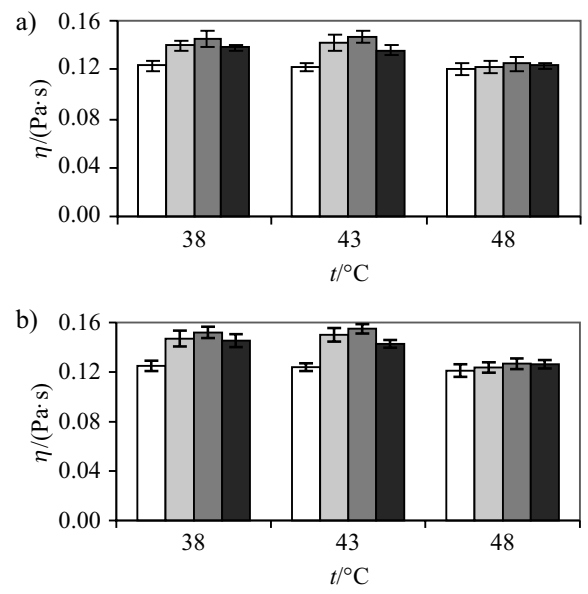

Fig. 11. Yoghurt viscosity (mean values \pm standard deviation) $v s$. operation temperature under: a) static and b) ultrasonic conditions at various values of clay/milk ratio $((m / V) /(\mathrm{g} / \mathrm{L})): \square R_{0}=0$, $R_{1}=1, \quad R_{2}=5, \quad R_{3}=7.5$
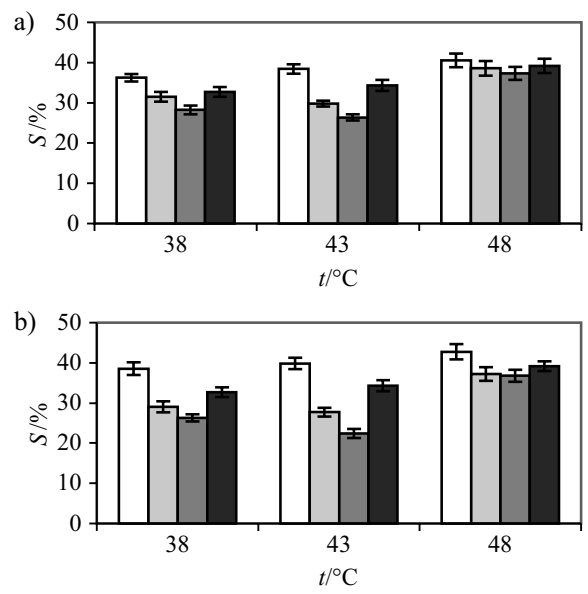

Fig. 12. Syneresis index (mean values \pm standard deviation) vs. operation temperature under: a) static and b) ultrasonic conditions at various values of clay/milk ratio $((m / V) /(\mathrm{g} / \mathrm{L}))$ : $\square R_{0}=0$, $R_{1}=1, \quad R_{2}=5$, $R_{3}=7.5$
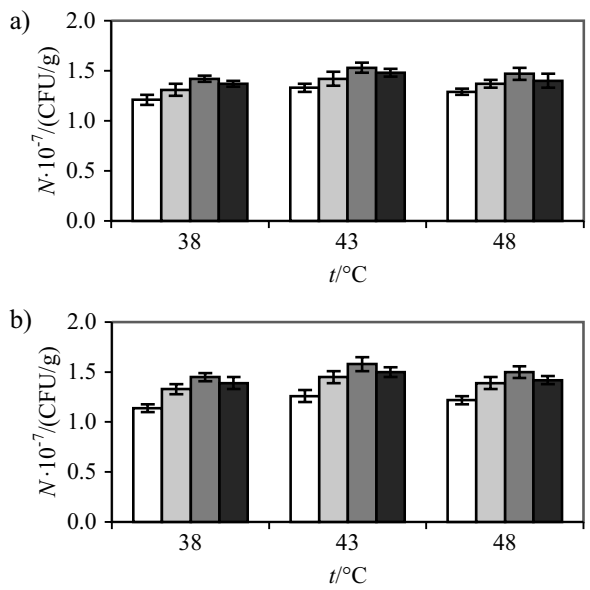

Fig. 13. Viable LAB number (mean values \pm standard deviation) vs. operation temperature under: a) static and b) ultrasonic conditions at various values of clay/milk ratio $((\mathrm{m} / \mathrm{V}) /(\mathrm{g} / \mathrm{L})): \square R_{0}=0$, $R_{1}=1, \quad R_{2}=5$, $R_{3}=7.5$

samples was observed at the highest levels of $t$ and $R$. Taking into account these aspects along with the heating and clay expenses, it can be concluded that the fermentation at the highest temperature and clay/milk ratio is unfavourable. In order to achieve a high yoghurt LAB concentration, the fermentation in the presence of anionic clay is more advantageous, as shown in Fig. 13.

Consequently, from the experiments conducted under various operation conditions and summarized in Table 1 (runs 1-24), only eight runs are favourable for obtaining a high yoghurt quality at low cost, namely those characterized by the following values of operational variables: $v=0$ and $35 \mathrm{kHz}, t=38$ and $43^{\circ} \mathrm{C}$ and $R=1$ and $5 \mathrm{~g} / \mathrm{L}$ (runs 2, 3, 6, 7, 14, 15, 18 and 19). The best yoghurt quality, characterized by maximum values of dynamic viscosity $(\eta=0.155 \mathrm{~Pa} \cdot \mathrm{s})$ and viable LAB concentration $\left(N=1.58 \cdot 10^{7}\right.$ $\mathrm{CFU} / \mathrm{g})$, minimum syneresis index $(S=22.37 \%)$ and a creamy coagulum, was obtained at $v_{2}=35 \mathrm{kHz}, t_{2}=43{ }^{\circ} \mathrm{C}$ and $R_{2}=5 \mathrm{~g} / \mathrm{L}$. 


\section{Statistical analysis of the data}

Final fermentation time, $\tau_{\mathrm{f}}$; minimum species concentration in the liquid phase in the presence of anionic clay, $\gamma_{\text {LA,min }}$ i equilibrium (saturation) species concentration in the solid phase, $s_{\text {LA,eq; }}$ species mass transfer coefficient in the liquid film, $k_{\mathrm{LA}} ;$ hourly yoghurt production, $P$; and yoghurt properties, i.e. dynamic viscosity, $\eta$; syneresis index, $S$; and viable LAB number, $N$, were selected as process-dependent variables (responses). These variables can be linked to the process-independent variables (factors), namely ultrasound frequency, $v$; operation temperature, $t$; and clay/milk ratio, $R$, with adequate regression equations. Factor and response values for an experimental set consisting of favourable runs to obtain a high yoghurt quality at low cost (runs 2, 3, 6, 7, 14, 15, 18 and 19 in Table 1 ) are given in Table 2 . Values of dimensionless factors were calculated depending on those of natural factors with the following equations:

$$
\begin{gathered}
x_{1}=\frac{v-17.5}{17.5} \\
x_{2}=\frac{t-40.5}{2.5} \\
x_{3}=\frac{R-3}{2}
\end{gathered}
$$

Processing the tabulated data based on characteristic procedure of a factorial experiment with 2 levels (44), the following regression equations were obtained:

$$
\begin{gathered}
\tau_{\mathrm{f}}=251.25+6.25 x_{1}-8.75 x_{2}+8.75 x_{3}+ \\
+1.25 x_{1} x_{2}-1.25 x_{1} x_{3}+3.75 x_{2} x_{3}-1.25 x_{1} x_{2} x_{3} \\
\gamma_{\mathrm{LA}, \min }=4.395-0.091 x_{1}+0.106 x_{2}-0.345 x_{3}- \\
-0.030 x_{1} x_{2}-0.021 x_{1} x_{3}-0.027 x_{1} x_{2} x_{3} \\
S_{\mathrm{LA}, \mathrm{eq}}=0.260+0.042 x_{1}+0.013 x_{2}-0.038 x_{3}-0.022 x_{1} x_{3} \\
k_{\mathrm{LA}}=\left(0.418+0.075 x_{1}+0.010 x_{2}-0.193 x_{3}-0.055 x_{1} x_{3}\right) \cdot 10^{-2} \\
P=33.960-0.728 x_{1}+1.247 x_{2}-0.988 x_{3}- \\
-0.230 x_{1} x_{2}+0.130 x_{1} x_{3}-0.560 x_{2} x_{3}+0.118 x_{1} x_{2} x_{3} \\
\eta=0.147+0.004 x_{1}+0.001 x_{2}+0.003 x_{3}
\end{gathered}
$$

$$
\begin{gathered}
S=27.683-1.295 x_{1}-1.105 x_{2}-1.852 x_{3}- \\
-0.217 x_{1} x_{2}-0.180 x_{1} x_{3}-0.355 x_{2} x_{3}-0.308 x_{1} x_{2} x_{3} \\
N=\left(1.436+0.016 x_{1}+0.059 x_{2}+0.059 x_{3}\right) \cdot 10^{7}
\end{gathered}
$$

According to Eqs. 17 and 18, final values of fermentation time, $\tau_{\mathrm{f}}$, are lower and minimum lactic acid concentration in the liquid phase, $\gamma_{\mathrm{LA}, \mathrm{min}}$ is higher in static operation mode (inferior level of ultrasound frequency, $x_{1}$ ) at higher temperature, $x_{2}$, and lower clay/milk ratio, $x_{3}$. The values of $\tau_{\mathrm{f}}$ and $\gamma_{\mathrm{LA} \text {,min }}$ depend on individual factors as well as on their double and triple interactions. Eqs. 19 and 20 emphasize that equilibrium (saturation) species concentration in the solid phase, $s_{\mathrm{LA}, \mathrm{eq}}$ and species mass transfer coefficient in the liquid film, $k_{\mathrm{LA}}$ are higher in ultrasound operation mode (higher level of $x_{1}$ ), higher level of $x_{2}$ and lower level of $x_{3}$. The values of $s_{\mathrm{LA}, \mathrm{eq}}$ and $k_{\mathrm{LA}}$ depend significantly on $x_{1}$ and $x_{3}$ factors as well as on the interaction of these factors, $x_{1} x_{3}$. Yoghurt production, $P$, is better at lower levels of $x_{1}$ and $x_{3}$, at higher level of $x_{2}$, and it is influenced by all process factors and their interactions (Eq. 21 ). Yoghurt viscosity, $\eta$, and viable $\mathrm{LAB}$ number, $N$, are higher and syneresis index, $S$, is lower at higher levels of all process factors (Eqs. 22-24). The $\eta$ and $N$ depend only on individual factors, whereas $S$ is influenced by individual factors and their interactions.

\section{Conclusions}

Characteristic lactic acid fermentation kinetics of yoghurt production was studied in the presence of hydrotalcite-type anionic clay particles under static and ultrasonic operation conditions. The anionic clay particles retained the LA produced in the fermentation medium and reduced its inhibitory effect on the LAB growth, whereas the ultrasonic field intensified the LA retention process by decreasing the boundary layer thickness and increasing the mass transfer rate.

A hydrotalcite-type anionic clay was synthesized by coprecipitation and further characterized by adsorption/ desorption isotherms at $77 \mathrm{~K}$ in order to determine its specific surface area $\left(3.6 \cdot 10^{5} \mathrm{~cm}^{2} / \mathrm{g}\right)$, pore size distribution (predominantly mesoporous structure) and mean pore diameter $(12.5 \mathrm{~nm})$. Lactic acid fermentation experiments

Table 2. Experimentation matrix

\begin{tabular}{rrrrrrrrrrrrr}
\hline Run & $x_{1}$ & $x_{2}$ & $x_{3}$ & $\frac{\tau_{\mathrm{f}}}{\min }$ & $\frac{\gamma_{\mathrm{LA}, \min }}{\mathrm{g} / \mathrm{L}}$ & $\frac{s_{\mathrm{LA}, \mathrm{eq}}}{\mathrm{g} / \mathrm{g}}$ & $\frac{k_{\mathrm{LA}} \cdot 10^{2}}{\mathrm{~cm} / \mathrm{min}}$ & $\frac{P}{\mathrm{~g} / \mathrm{h}}$ & $\frac{\eta}{\mathrm{Pa} \cdot \mathrm{s}}$ & $\frac{S}{\%}$ & $\frac{N \cdot 10^{-7}}{\mathrm{CFU} / \mathrm{g}}$ \\
\hline 2 & -1 & -1 & -1 & 250 & 4.696 & 0.225 & 0.47 & 33.65 & 0.140 & 31.49 & 1.31 \\
3 & -1 & -1 & 1 & 260 & 4.005 & 0.194 & 0.20 & 32.77 & 0.145 & 28.24 & 1.42 \\
6 & -1 & 1 & -1 & 240 & 4.923 & 0.243 & 0.49 & 37.96 & 0.142 & 29.81 & 1.42 \\
7 & -1 & 1 & 1 & 250 & 4.319 & 0.210 & 0.21 & 34.37 & 0.147 & 26.37 & 1.53 \\
14 & 1 & -1 & -1 & 260 & 4.562 & 0.350 & 0.73 & 32.63 & 0.147 & 29.08 & 1.33 \\
15 & 1 & -1 & 1 & 270 & 3.893 & 0.220 & 0.23 & 31.80 & 0.152 & 26.34 & 1.45 \\
18 & 1 & 1 & -1 & 250 & 4.777 & 0.374 & 0.75 & 35.55 & 0.150 & 27.76 & 1.45 \\
19 & 1 & 1 & 1 & 260 & 3.982 & 0.264 & 0.26 & 32.95 & 0.155 & 22.37 & 1.58 \\
\hline
\end{tabular}

$\tau_{\mathrm{f}}$ final fermentation time; $\gamma_{\mathrm{LA}, \min }=$ minimum lactic acid (LA) concentration in the liquid phase in the presence of anionic clay; $s_{\mathrm{LA}, \mathrm{eq}}=$ equilibrium LA concentration in the solid phase; $k_{\mathrm{LA}}=$ mass transfer coefficient in the liquid film; $P=$ hourly yoghurt production; $\eta=$ =yoghurt dynamic viscosity; $S=$ syneresis index; $N=$ viable LAB number 
were performed using as fermentation medium low-fat $(1.5 \%)$ pasteurized milk inoculated with a yoghurt starter culture. The anionic clay was added to the fermentation medium at $\mathrm{pH}=5.0-5.1$, when the $\mathrm{LAB}$ growth was considered optimal, and LA retention onto anionic clay particles was obtained with and without ultrasound field. The experimental study was conducted under static and ultrasonic conditions (at $v=0$ and $35 \mathrm{kHz}$ ), at three operation temperatures $\left(t=38,43\right.$ and $48^{\circ} \mathrm{C}$ ) and four clay/milk ratios $(R=0,1,5$ and $7.5 \mathrm{~g} / \mathrm{L})$. Twenty four experimental curves describing the variation of LA concentration in the liquid phase, $\gamma_{\text {LA }}$, with fermentation time, $\tau$, were obtained. It was concluded that the final fermentation time, $\tau_{\mathrm{f}}$, was lower in static runs and decreased with the increase of $t$ and the decrease of $R$. A physical and microbiological analyses of the fermented product highlighted that only eight experimental runs ( $v=0$ and $35 \mathrm{kHz}, t=38$ and $43{ }^{\circ} \mathrm{C}$ and $R=1$ and $5 \mathrm{~g} / \mathrm{L}$ ) were favourable for preparation of a high quality yoghurt at low cost. The best yoghurt quality, characterized by maximum viscosity and viable LAB number, minimum syneresis index and creamy coagulum, was obtained at $v=35 \mathrm{kHz}, t=43^{\circ} \mathrm{C}$ and $R=5 \mathrm{~g} / \mathrm{L}$. Due to a high content of viable $\mathrm{LAB}$ and to the presence of clay with antacid properties, this product can have significant health benefits.

A mathematical model, assuming a perfect mixing of fermentation medium and mass transfer resistance concentrated in a static liquid film around the anionic clay particle, was selected to describe the lactic acid fermentation accompanied by LA retention onto clay particles. By solving the model equations depending on experimental data, i.e. $\gamma_{\mathrm{LA}}=\gamma_{\mathrm{LA}}(v, t, R, \tau)$, the equilibrium (saturation) LA concentration in the solid phase, $s_{\mathrm{LA}, \mathrm{eq}}$, and the LA mass transfer coefficient in the liquid film, $k_{\mathrm{LA}}$, were estimated under various operation conditions. Values obtained for $s_{\text {LA,eq }}(0.171-0.383 \mathrm{~g} / \mathrm{g})$ and $k_{\mathrm{LA}}(0.0018-0.0077 \mathrm{~cm} / \mathrm{min})$, in a good agreement with data reported in the related literature, were higher in ultrasonic runs, with higher values of $t$ and lower values of $R$.

A statistical analysis of the data based on a $2^{3}$ factorial experiment was performed for the runs selected as favourable. Regression equations linking the process responses to their factors were established and commented.

\section{References}

1. A.Y. Tamine, R. K. Robinson: Yoghurt: Science and Technology, CRC Press LLC, Boca Raton, FL, USA (1999).

2. T. Vasiljevic, N.P. Shah: Cultured Milk and Yogurt. In: Dairy Processing and Quality Assurance, R.C. Chandan, A. Kilara, N.P. Shah (Eds.), John Wiley \& Sons, Hoboken, NJ, USA (2008).

3. I.H. Aljundi, J.M. Belovich, O. Talu, Adsorption of lactic acid from fermentation broth and aqueous solutions on Zeolite molecular sieves, Chem. Eng. Sci. 60 (2005) 5004-5009. http://dx.doi.org/10.1016/j.ces.2005.04.034

4. S.A. Ataei, E. Vasheghani-Farahani, In situ separation of lactic acid from fermentation broth using ion exchange resins, J. Ind. Microbiol. Biotechnol. 35 (2008) 1229-1233. http://dx.doi.org/10.1007/s10295-008-0418-6

5. A. Bouguettoucha, B. Balannec, A. Amrane, Unstructured models for lactic acid fermentation - A review, Food Technol. Biotechnol. 49 (2011) 3-12.
6. A.V. Sosa, J. Ochoa, N.I. Perotti, Modeling of direct recovery of lactic acid from whole broths by ion exchange adsorption, Bioseparation, 9 (2001) 283-289.

http://dx.doi.org/10.1023/A:1011165810823

7. Y. Sun, Y.L. Li, S. Bai, Z.D. Hu, Modeling and simulation of an in situ product removal process for lactic acid production in an airlift bioreactor, Ind. Eng. Chem. Res. 38 (1999) 32903295.

http://dx.doi.org/10.1021/ie990090k

8. P. von Frieling, K. Schügerl, Recovery of lactic acid from aqueous model solutions and fermentation broths, Process Biochem. 34 (1999) 685-696.

http://dx.doi.org/10.1016/S0032-9592(98)00143-5

9. M.T. Gao, T. Shimamura, N. Ishida, E. Nagamori, H. Takahashi, S. Umemoto et al., Extractive lactic acid fermentation with tri-n-decylamine as the extractant, Enzyme Microb. Technol. 44 (2009) 350-354.

http://dx.doi.org/10.1016/j.enzmictec.2008.12.001

10. T. Hano, M. Matsumoto, S. Uenoyama, T. Ohtake, Y. Kawano, S. Miura, Separation of lactic acid from fermented broth by solvent extraction, Bioseparation, 3 (1992-1993) 321-326.

11. J.H. Choi, S.H. Kim, S.H. Moon, Recovery of lactic acid from sodium lactate by ion substitution using ion-exchange membrane, Sep. Purif. Technol. 28 (2002) 69-79. http://dx.doi.org/10.1016/S1383-5866(02)00014-X

12. P. Vonktaveesuk, M. Tonokava, A. Ishizaki, Stimulation of the rate of L-lactate fermentation using Lactococcus lactis IO-1 by periodic electrodialysis, J. Ferment. Technol. 77 (1994) 508-512.

http://dx.doi.org/10.1016/0922-338X(94)90119-8

13. S.S. Yi, Y.C. Lu, G.S. Luo, Separation and concentration of lactic acid by electro-electrodialysis, Sep. Purif. Technol. 60 (2008) 308-314.

http://dx.doi.org/10.1016/j.seppur.2007.09.004

14. L.K. Ju, C.C. Chen, Adsorption characteristics of polyvinylpyridine and activated carbon for lactic acid recovery from fermentation of Lactobacillus delbrueckii, Sep. Sci. Technol. 33 (1998) 1423-1437. http://dx.doi.org/10.1080/01496399808545058

15. X. Cao, H.S. Yun, Y.M. Koo, Recovery of L-(+)-lactic acid by anion exchange resin Amberlite IRA-400, Biochem. Eng. J. 11 (2002) 189-196. http://dx.doi.org/10.1016/S1369-703X(02)00024-4

16. J.M. Monteagudo, M. Aldavero, Production of L-lactic acid by Lactobacillus delbrueckii in chemostat culture using an anion exchange resins system, J. Chem. Technol. Biotechnol. 74 (1999) 627-634.

http://dx.doi.org/10.1002/(SICI)1097-4660(199907)74:7<627: :AID-JCTB84>3.3.CO;2-B

17. A. Srivastava, P.K. Roychoudhury, V. Sahai, Extractive lactic acid fermentation using ion-exchange resin, Biotechnol. Bioeng. 39 (1992) 607-613. http://dx.doi.org/10.1002/bit.260390604

18. L. Xu, S. Luan, Z. Zheng, X. Ding, P. Cen, Simultaneous ionexchange and adsorption of lactic acid on D354 resin, Chinese J. Chem. Eng. 3 (1995) 82-87.

19. W.J. Lee, J.A. Lucey, Formation and physical properties of yoghurt, Asian-Aust. J. Anim. Sci. 23 (2010) 1127-1136.

20. D. Petridis, G. Dimitreli, S. Chrysalidou, P. Akakiadou, Optimization of the rheological and sensory properties of stirred yogurt as affected by chemical composition and heat treatment of buffalo milk, J. Food Res. 2 (2013) 55-71. http://dx.doi.org/10.5539/jfr.v2n6p55

21. Q.Z. Zhao, J.S. Wang, M.M. Zhao, Y.M. Jiang, C. Chun, Effect of casein hydrolysates on yogurt fermentation and texture properties during storage, Food Technol. Biotechnol. 44 (2006) 429-434. 
22. I. Ahmad, M. Gulzar, F. Shahzad, M. Yaqub, T. Zhoor, Quality assessment of yoghurt produced at large (industrial) and small scale, J. Anim. Plant Sci. 23 (2013) 58-61.

23. J.A. Bhat, M.I. Naik, R.K. Tenguria, Isolation of lactic acid bacteria under low temperature for the preparation of yogurt, IJABPT, 4 (2013) 293-298.

24. M. Ginovart, D. López, J. Valls, M. Silbert, Simulation modelling of bacterial growth in yoghurt, Int. J. Food Microbiol. 73 (2002) 415-425. http://dx.doi.org/10.1016/S0168-1605(01)00668-7

25. Z.M. Bai, Z.Y. Wang, T.G. Zhang, F. Fu, N. Yang, Characterization and friction performances of $\mathrm{Co}-\mathrm{Al}$-layered doublemetal hydroxides synthesized in the presence of dodecylsulfate, Appl. Clay Sci. 75-76 (2013) 22-27. http://dx.doi.org/10.1016/j.clay.2013.03.001

26. U. Constantino, V. Ambrogi, M. Nocchetti, L. Perioli, Hydrotalcite-like compounds: Versatile layered hosts of molecular anions with biological activity, Micropor. Mesopor. Mat. 107 (2008) 149-160. http://dx.doi.org/10.1016/j.micromeso.2007.02.005

27. W.T. Reichle, Synthesis of anionic clay minerals (mixed metal hydroxides, hydrotalcite), Solid State Ionics, 22 (1986) 135-141. http://dx.doi.org/10.1016/0167-2738(86)90067-6

28. A. Azzouz, T. Sajin, I.D. Nistor, A., Crăciun, G. Duca, Proceeding of lactic bacteria cultivation. Patent MD 2696 F1 (2006).

29. K. Katsuki, A. Okada, Gastric antacid. US Patent 8216608 (2012).

30. K. Katsuki, A. Okada, Agent for treating ulcer. US Patent 8372429 (2013).

31. S.E. Miederer, M. Wirtz, B. Fladung, Acid neutralization and bile acid binding capacity of hydrotalcite compared with other antacids: An in vitro study, Chin. J. Dig. Dis. 4 (2003) $140-146$. http://dx.doi.org/10.1046/j.1443-9573.2003.00132.x

32. Y.L. Xiao, Y.Q. Nie, X.H. Hou, P.Y. Xie, J.Y. Fang, Y.Z. Yuan et al., The efficacy, safety and cost-effectiveness of hydrotalcite versus esomeprazole in on-demand therapy of NERD: A multicenter, randomized, open-label study in China, Chin. J. Dig. Dis. 14 (2013) 463-468. http://dx.doi.org/10.1111/1751-2980.12069

33. Handbook on Applications of Ultrasound: Sonochemistry for Sustainability, D. Chen, S.K. Sharma, A. Mudhoo (Eds.), CRC Press Taylor \& Francis Group LLC, Boca Raton, FL, USA (2012).
34. W. Qin, Y. Yuan, Y. Dai, Effect of ultrasound on desorption equilibrium, Chinese J. Chem. Eng. 9 (2001) 427-430.

35. F. Cavani, F. Trifirò, A.Vaccari, Hydrotalcite-type anionic clays: Preparation, properties and applications, Catal. Today, 11 (1991) 173-301. http://dx.doi.org/10.1016/0920-5861(91)80068-K

36. V.A. Aruş, Contributions concerning the kinetics of fermentation process in the presence of kinetic modifiers, $\mathrm{PhD}$ Thesis, Politehnica University of Bucharest, Bucharest, Romania (2010).

37. V.A. Aruş, G. Jinescu, I.D. Nistor, N.D. Miron, A.V. Ursu, G. Isopencu, A.M. Mareș, Preparation and characterization of anionic clays used like kinetic modifiers in lactic fermentation, Rev. Chim. (Bucharest), 61 (2010) 1100-1104.

38. V.A. Aruş, O.C. Pârvulescu, C. Jinescu, I.D. Nistor, Mathematical modelling of the retention process of lactic acid on anionic clay particles using mechanical mixing for process intensification, Rev. Chim. (Bucharest), 62 (2011) 1180-1184.

39. A. Azzouz, V.A. Aruş, N. Platon, K. Ghomari, I.D. Nistor, T.C. Shiao, R. Roy, Polyol-modified layered double hydroxides with attenuated basicity for a truly reversible capture of CO2, Adsorption, 19 (2013) 909-918. http://dx.doi.org/10.1007/s10450-013-9498-3

40. Difco ${ }^{\mathrm{TM}} \& \mathrm{BBL}^{\mathrm{TM}}$ Manual: Manual of microbiological culture media, M.J. Zimbro, D.A. Power, S.M. Miller, G.E. Wilson, J.A. Johnson (Eds.), BD Diagnostics - Diagnostic Systems, Sparks, MD, USA (2009).

41. N. Kearney, H.M. Stack, J.T. Tobin, V. Chaurin, M.A. Fenelon, G.F. Fitzgerald et al., Lactobacillus paracasei NFBC 338 producing recombinant beta-glucan positively influences the functional properties of yoghurt, Int. Dairy J. 21 (2011) 561567. http://dx.doi.org/10.1016/j.idairyj.2011.03.002

42. M.S. Tsevdou, E.G. Eleftheriou, P.S. Taoukis, Transglutaminase treatment of thermally and high pressure processed milk: Effects on the properties and storage stability of set yoghurt, Innov. Food Sci. Emerg. Tech. 17 (2013) 144-152. http://dx.doi.org/10.1016/j.ifset.2012.11.004

43. R.B. Magenis, E.S. Prudêncio, R.D.M.C. Amboni, N.G. Cerqueira Júnior, R.V.B. Oliveira, V. Soldi, H.D. Benedet, Compositional and psysical properties of yogurts manufactured from milk and whey cheese concentrated by ultrafiltration, Int. J. Food Sci. Tech. 41 (2006) 560-568. http://dx.doi.org/10.1111/j.1365-2621.2005.01100.x

44. T. Dobre, J. Sanchez Marcano: Chemical Engineering - Modelling, Simulation and Similitude, Wiley-VCH, Weinheim, Germany (2007). 